\title{
Review Venous Thromboembolism Risk with Anti-Osteoporosis Drugs
}

\author{
Kawtar Nassar*, Wafae Rachidi, Saadia Janani, Ouafa Mkinsi \\ Department of Rheumatology, Ibn Rochd University Hospital Center, Medicine and Pharmacy University of Casablanca, \\ Casablanca, Morocco \\ Email: *nassarkawtar@gmail.com
}

How to cite this paper: Nassar, K., Rachidi, W., Janani, S. and Mkinsi, O. (2018) Review Venous Thromboembolism Risk with Anti-Osteoporosis Drugs. Open Journal of Rheumatology and Autoimmune Diseases, 8, 111-119.

https://doi.org/10.4236/ojra.2018.84012

Received: July 18, 2018

Accepted: October 27, 2018

Published: October 30, 2018

Copyright (c) 2018 by authors and Scientific Research Publishing Inc. This work is licensed under the Creative Commons Attribution International License (CC BY 4.0).

http://creativecommons.org/licenses/by/4.0/

\begin{abstract}
Osteoporosis is the most common skeletal diseases, predisposing the patient to an increased risk of fractures. It is an important health issue linked to increased morbidity and mortality. Prevention and treatment strategies are now well defined and are always updating. Indeed, the therapeutic decision is based on the individual risk of fracture, efficiency and degree of therapeutic tolerance. However, some side effects, although rare can be attributed to drugs used. The benefit and risks of prescription drugs can be optimized by choosing the right time and the right treatment. The purpose of this article is the study of thromboembolic risk of various drugs recommended in osteoporosis. Furthermore we discuss preventive measures, and the different approaches after the first event.
\end{abstract}

\section{Keywords}

Osteoporosis, Venous Thrombosis, Drugs, Estrogens, Progestins

\section{Introduction}

Since the international consensus conference in Hong Kong in 1993, that of Amsterdam in 1996, and the NIH in 2001, osteoporosis has been defined by a gradual decrease in bone mass and qualitative alterations of bone tissue, hence the bone resistance, predisposing the patient to an increased risk of fractures [1]. The consequences in terms of morbidity and mortality are high. The various therapeutic methods currently available have demonstrated a beneficial effect on bone mass and the risk of fractures [2]. However, some medications may be associated with side effects, including thromboembolic. Their knowledge, the usual precautions of prescription and follow-up must be integrated in the strategies of the long-term management of the osteoporotic patients. This article will 
focus on data on the thromboembolic risks of anti-osteoporotic drugs.

\section{Current State of Knowledge}

\section{Anti-0steoporotics: Interest and Concept of Prescription}

The WHO has defined diagnostic criteria for postmenopausal osteoporosis, based on measurement of bone mineral density (T-Score $<-2.5$ ). National and international guidelines have established different strategies for each type of osteoporosis, including therapeutic ones. The main objective is to prevent fracture onset or recurrence [3].

The therapeutic decision is based on the individual risk of fracture in five to ten years, the effectiveness and the degree of therapeutic tolerance. In fact, two situations lead to the initiation of an anti-osteoporotic treatment: The presence of an osteoporotic fracture requires treatment, after correction of vitamin-calcium deficiency and the elimination of differential diagnoses of osteopathies weakening. In addition, it is based on the risk factors for bone fragility and the densitometric value for patients without a fracture history. Therapeutic management is based on the combination of drug treatments aimed at bone and compliance with preventive measures of the risk of falling, the correction of vitamin D deficiency to the optimal threshold of $30 \mathrm{ng} / \mathrm{ml}$ and a daily intake optimal calcium [4].

Effective treatments are now available to reduce the incidence of osteoporotic fractures. They reduce by $30 \%$ to $65 \%$ the occurrence of vertebral or non-vertebral fractures [5]. On the other hand, few studies have compared the different molecules with each other. Proposals for therapeutic classification are therefore developed without a strategy based on a superiority of one drug over another.

Many factors intervene for the choice of the treatment to initiate, among which [6]: The authorized and/or reimbursed indications, the effectiveness on the vertebral and non-vertebral fractures, the extra-osseous effect, and the persistence at the end of the treatment, compliance, therapeutic tolerance and cost.

Patient-related factors include: The risk of extra-virulent pathology, life expectancy, patient motivation, history, individual cost-benefit ratio, preferences for the mode and timing of treatment.

Therapeutic possibilities are (in alphabetical order): zoledronic acid (5 $\mathrm{mg}$ infusion once a year), alendronate (70 mg weekly), denosumab (60 mg one SC injection every six months), ibandronate $(150 \mathrm{mg} / \mathrm{month})$, raloxifene $(60 \mathrm{mg} /$ day $)$, strontium ranelate ( $2 \mathrm{~g} /$ day), risedronate ( $35 \mathrm{mg}$ weekly), teriparatide ( $20 \mathrm{ug} /$ day), hormone therapy for menopause (THM).

Moreover, if exposure to certain drugs is considered as a potential environmental risk factor for venous thromboembolic disease and excluding the involvement of antipsychotics, evoked by numerous observational studies and estroprogestative contraception whose excess risk is well established, the risk associated with some treatments for osteoporosis is also documented [7]. What are these medications? And what is the link between these and the occurrence of 
vascular events?

\section{Medications for Osteoporosis and Thromboembolic Risk}

\subsection{Hormonal Treatment of Postmenopausal Osteoporosis}

Hormone therapy in menopause (THM) consists of an estrogen derivative, with or without a progestin [8]. Available orally or transdermally, it is the most effective treatment for postmenopausal hot flashes, regardless of age. The benefits clearly outweigh the risks for women under 60 or ten years after menopause [9]. Adequate estrogen replacement therapy restores hormone deficiency and prevents peri and post-menopausal bone loss as well as primary prevention of osteoporotic fractures.

Nevertheless, the THM is not indicated as first-line therapy for preventing postmenopausal osteoporosis in the absence of the climacteric syndrome. It may be indicated as a second-line therapy in postmenopausal osteoporotic women at high risk of fracture, in case of intolerance or contraindication to recommended treatments [10].

The WHI study demonstrated a reduction in fracture risk (all fractures combined) in the "estrogen/progestin" arm of $24 \%$ (relative risk of 0.76 for a confidence interval of $0.69-0.83$, i.e. $95 \%$ ) [11].

In addition, it is essential that THM be introduced at the lowest effective dose, for the shortest possible time. The precise duration is not well defined. Based on the WHI randomized trial, the treatment was associated with a significant decrease in osteoporotic fractures after five years. The therapeutic relay is possible from the outset in case of high risk of fracture. The regular reassessment of the benefit/risk ratio is essential, clean for each woman.

However, the risk of developing venous thromboembolism (VTE) is increased two to four times in women using oral THM. Due to their hepatic effect, there is an increase in the production of pro-inflammatory factors and the combination with a synthetic progestin amplifies the risk of cardiovascular events [12]. Also, estrogens exert a paradoxical action on the vascular wall: Protective effect when they are administered before the appearance of vascular endothelial lesions and pro-inflammatory on an already damaged endothelium, which can break a vulnerable atheromatous plaque and hypercoagulability [13].

In addition to the neoplastic risk, the French ESTHER study [14], as well as the randomized trials, WHI and HERS, [11] [15] showed that the risk of venous thromboembolic accident under oral THM was highest, hence the interest of bio-identical hormones in this case $17 \beta$-estradiol and progesterone.

However, from the analysis of the current data, the benefit/risk ratio does not seem to be unfavorable for the hormonal treatment used in women at risk of osteoporosis and at the beginning of the menopause [15].

Prevention of Thromboembolic Risk during Hormonal Treatment The prescription of THM should follow the recommendations for indication 
during postmenopausal osteoporosis. It should be initiated at the lowest effective dose for the shortest possible time, especially in the first year of use, during which the risk of VTEV appears to be high.

However, when the indication is necessary, it is legitimate to consider first-line transdermal THM, given the toxicity data for the oral route.

The data suggest an exponential increase in risk in the presence of thrombophilia in patients with no history of thrombosis [16]. Therefore, it is desirable to provide an alternative of THM, if necessary.

In practice, in the event of occurrence of thrombosis under hormonal treatment of menopause, it is forbidden to continue it, especially in patients with a history of thrombosis. In a randomized placebo-controlled trial [17] evaluating the risk of vascular complications under oral THM in postmenopausal women with a history of VTE, treatment was discontinued early due to thrombotic relapse rates (10.7\% versus $2.3 \%)$ under placebo.

\subsection{Selective Estrogen Receptor Modulators (SERMs)}

Selective estrogen receptor modulators (SERMs) are anti-osteoclastic agents. Like lasofoxifene, raloxifene, the third-generation SERMs have proven their action in the prevention and treatment of postmenopausal osteoporosis. Tamoxifen, tormemefine, raloxifene have been shown to be effective in the prevention and treatment of breast cancer and clomiphene in infertility [18]. Given the existence of two types of estrogen cellular receptors, these molecules offer the advantage of the multiplicity of tissue action. They retained the agonist effect of estrogen on the bone, reducing osteoclastic hyperactivity, particularly on the trabecular bone, while being antagonistic or neutral on the gynecological sphere.

The MORE study is a large clinical trial, involving 7705 women with low BMD (T-score $<-2.5$ ), with an average age of 67 years and one or more prevalent vertebral compression (one third of patients). Raloxifene $60 \mathrm{mg} / \mathrm{d}$ taken for 3 years slowed postmenopausal bone loss with a $37 \%$ decrease in the incidence of vertebral fractures [19].

The 3-year extension of the MORE study (CORE study) showed, in densitometric patients, a gain of $+2.2 \%$ in the lumbar spine and +3 in the upper end of the femur in naïve bisphosphonate patients. However, there was no difference in the incidence of FNV between women treated and those who received placebo $(\mathrm{RR}=1.00[0.82-1.21])$.

In practice, SERMs, especially raloxifene, reduce the biomarkers of bone remodeling. Densitometric gain in the lumbar spine, femoral neck and whole body has been proven with reduced risk of vertebral fracture (with or without prevalent vertebral fracture) but not peripheral.

A duration of at least four years has been proposed. The optimal duration of 8 years remains an individual decision after regular reassessment of the risk [20].

In addition, discontinuation of raloxifene results in a rapid decrease in bone density, which in women at high risk of fracture is a therapeutic paradigm. 
In contrast to THMs, SERMs, especially raloxifene, are not indicated in case of climacteric syndrome. A significant increase in hot flashes and muscle cramps is observed and especially a significant increase in the risk of phlebitis (risk multiplied by 3.5).

On the cardiovascular level, there is an increase in the risk of venous thromboembolism in a manner similar to estrogens by the oral route.

In the randomized placebo-controlled trial (RUTH) to determine the effect of raloxifene on risk of coronary events and risk of breast cancer, raloxifene was associated with excess VTE (RR: 1, 44, 95\% CI: 1.06 - 1.95); the risk being multiplied by 1.5 to two.

There is no impact on coronary risk and a small increase in the risk of stroke has been reported among older women. The meta-analysis of Adomaityte J et al. confirmed these results [21].

\section{Preventive Measures during Treatment with SERMs}

Existing data are clearly insufficient to make valid recommendations. Like THM, the duration of raloxifene therapy should be the most minimal effective. When the indication is required, the transdermal route should be preferred. Therapeutic relay may be considered whenever the benefit-risk balance is no longer deemed to be as favorable as at the beginning of menopause and/or after several years of use.

The occurrence of thrombosis during treatment is a contraindication, especially in patients with a history of thromboembolism.

The concomitant use of platelet aggregation inhibitors to prevent the risk of thrombotic injury is not associated with a change in thromboembolic risk. There was no significant difference between the two groups in the RUTH assay (HR $1.44,95 \%$ CI $0.98,2.10)$ and (HR 1.37, 95\% CI 0.83, 2.27) $(\mathrm{p}=0.88)$ [22].

\subsection{Strontium Ranelate}

Strontium ranelate (RS) consists of 2 stable strontium atoms and ranelate salt. At the bone level, its mechanism of action is twofold: It acts on both osteoformation and resorption. Its anti-fracture efficacy has been widely demonstrated in clinical trials in patients naive to any antiosteoporotic treatment [23]. It is indicated in postmenopausal osteoporosis, in the prevention or recurrent fracture, and it represents a therapeutic alternative in case of contraindication or intolerance to bisphosphonates [24]. The optimal duration of treatment is 8 years.

However, some side effects may be associated, including venous thromboembolism and DRESS. The annual incidence reported in the regional pharmacovigilance center registry is $2.7 \%$ with strontium ranelate versus $1.9 \%$ with placebo, a relative risk of 1.42 [25]. Similarly, in the French study of Annie-Pierre et al. [26] Among cardiovascular adverse events, venous thromboembolic events were greater (93/104), deep vein thrombosis (54\%), pulmonary embolism (34\%), and $2 \%$ central vein thrombosis. of the retina. At least one risk factor for venous thrombosis was found in $28 \%$ of patients. 
To explain their mechanisms of vascular action, some studies found a decrease in the concentration of homocysteine after treatment with RS, others did not find changes in the biological parameters of hemostasis, before and after two months of treatment [27] [28].

\section{Preventive Approaches under Strontium Ranelate}

The French Agency for Health Safety of Health Products (AFSSAPS) and the Poison Control and Pharmacovigilance Center had issued a warning regarding the use of SR. The Transparency Committee re-evaluated this medicine on May 11, 2011 [29]. The indication was thus restricted to patients under 80 years of age, not immobilized with a contraindication/intolerance to bisphosphonates, without risk factors for venous thromboembolic events (ATEV).

Despite the low risk of reported venous thromboembolism, the benefit-risk balance has recently been re-evaluated by the European Medicines Agency. Thus, RS should not be prescribed in patients with a history of venous thromboembolic disease or in elderly patients at risk for venous thrombosis. A warning must also be given regarding the risk of hypersensitivity syndrome (or DRESS syndrome) and the appearance at the beginning of treatment of a generalized rash associated with a fever must lead to its arrest and to a specialized opinion [29].

\section{Conclusions}

Although they occupy a place in the therapeutic arsenal of osteoporosis, with an efficiency close to that of bisphosphonates, the anti-osteoporotic drugs potentially associated with venous thromboembolic disease are: The hormonal treatment of menopause, selective osteogenic receptor modulators and strontium ranelate. The physiopathogenic link between these and the thrombotic risk is still heterogeneous. Despite their bone benefit, increasing evidence suggests that patients with VTE will be at greater risk for subsequent arterial events. In the future, we hope that epidemiological studies in outpatient and inpatient medicine may lead to more comprehensive analyzes of the undesirable effects of these drugs, the rationalization of their prescription and the vigilant monitoring of patients.

\section{1) What is known about this topic}

- Osteoporosis is a real public health issue, linked to the increase in morbidity and mortality.

- The therapeutic decision is based on the individual risk of fracture, the effectiveness and the degree of the therapeutic tolerance.

The anti-osteoporotic drugs potentially associated with thromboembolic venous disease are: Menopausal hormone therapy, selective oestrogenic hormone modulators and strontium ranelate.

\section{2) What the study brings back}

- The benefit and risk ratio of prescribed drugs can only be optimized by choosing the right time and the right treatment. 
- Despite their bone benefit, recent, growing evidence suggests that patients with VTE may be at higher risk for subsequent events.

- The knowledge of the thromboembolic risk, the usual precautions of prescription and follow-up must be integrated in the strategies of the long-term care of the osteoporotic patients.

\section{Authors' Contributions}

Kawtar Nassar: The author; Wafae Rachidi, Saadia Janani, Ouafa Mkinsi: Co-authors.

\section{Conflicts of Interest}

None.

\section{References}

[1] Montalcini, T., Gorgone, G., Fava, A., Castagna, A., Rondinelli, I. and Pugia, A. (2001) NIH Consensus Development Panel on Osteoporosis Prevention, Diagnosis, and Therapy. Osteoporosisprevention, Diagnosis, and Therapy. JAMA, 285, 785-795. https://doi.org/10.1001/jama.285.6.785

[2] Rousière, M. (2011) De l'importance de prendre en charge l'ostéoporose [The Importance of Taking Care of Osteoporosis]. La Presse Médicale, 40, 900-909.

https://doi.org/10.1016/j.lpm.2011.02.025

[3] Dargent-Molina, P., Benhamou, C.L., Cortet, B., Sutter, B. and Thomas, T. (2007) Vers une évaluation globale du risque fracturaire [Devising Global Strategies for Fracture-Risk Evaluation]. Revue du Rhumatisme, 74, 455-460. https://doi.org/10.1016/j.rhum.2006.11.016

[4] Briot, K., Cortet, B., Thomas, T., Audran, M., Blaine, H., Breuil, V., et al. (2012) Actualisation 2012 des recommandations françaises du traitement médicamenteux de l'ostéoporose post-ménopausique. Revue du Rhumatisme, 79, 264-274. https://doi.org/10.1016/j.rhum.2012.02.006

[5] Audran, M. (2006) Chronologie des traitements de l'ostéoporose [Drug Combination Strategies for Osteoporosis]. Revue du Rhumatisme, 73, 686-691. https://doi.org/10.1016/j.rhum.2006.02.013

[6] Thomas, T. (2009) Ostéoporose postménopausique: Le point sur sa prise en charge [Postmenopausal Osteoporosis: Current Management of the Disease]. Médecine Nucléaire, 33, 2-6. https://doi.org/10.1016/j.mednuc.2008.09.009

[7] Lacut, K., Mottier, D. and Pottier, P. (2008) Médicaments et maladie veineuse thromboembolique [Drugs and Venous Thromboembolism]. Revue de Pneumologie Clinique, 64, 290-297. https://doi.org/10.1016/j.pneumo.2008.09.005

[8] Reginster, J.Y., Neuprez, A., Lecart, M.P., Sarlet, N., Distèche, S. and Bruyère, O. (2014) Treatment of Post-Menopausic Osteoporosis: What's New in 2014? Revue médicale de Liège, 69, 441-453.

[9] Tella, S.H. and Gallagher, J.C. (2014) Prevention and Treatment of Postmenopausal Osteoporosis. The Journal of Steroid Biochemistry and Molecular Biology, 142, 155-170. https://doi.org/10.1016/j.jsbmb.2013.09.008

[10] Reginster, J.Y., Neuprez, A., Dardenne, N., Beaudart, C., Emonts, P. and Bruyere, O. (2014) Efficacy and Safety of Currently Marketed Anti-Osteoporosis Medications. 
Best Practice \& Research: Clinical Endocrinology \& Metabolism, 28, 809-834. https://doi.org/10.1016/j.beem.2014.09.003

[11] Cauley, J.A., Robbins, J., Chen, Z., Cummings, S.R., Jackson, R.D., LaCroix, A.Z., et al. (2003) Effects of Estrogenplus Progestin on the Risk of Fracture Andbone Mineral Density. The Women's HealthInitiative Randomized Trial. JAMA, 290, 1729-1738. https://doi.org/10.1001/jama.290.13.1729

[12] Gomes, M.P. and Deitcher, S.R. (2004) Risk of Venous Thromboembolic Disease Associated with Hormonal Contraceptives and Hormone Replacement Therapy: A Clinical Review. Archives of Internal Medicine, 164, 1965-1976. https://doi.org/10.1001/archinte.164.18.1965

[13] Claude, R. and Florence, T. (2006) Place du traitement hormonal substitutif dans la prise en charge de l'ostéoporose postménopausique et la prévention du risque fracturaire [Hormone Replacement Therapy in the Management of Postmenopausal Osteoporosis and Prevention of Fracture Risk]. La Presse Médicale, 35, 1557-1563. https://doi.org/10.1016/S0755-4982(06)74851-5

[14] Scarabin, P.Y., Oger, E., Plu-Bureau, G. and ESTHER Study Group (2003) Differential Associations of Oral Andtransdermal Oestrogen Replacement Therapy with Venous Thromboembolism Risk. The Lancet, 362, 428-432.

https://doi.org/10.1016/S0140-6736(03)14066-4

[15] Grady, D., Wenger, N.K., Herrington, D., Khan, S., Furberg, C., Hunninghake, D., et al. (2000) Postmenopausal Hormone Therapyincreases Risk for Venous Thromboembolic Disease: The Heartand Estrogen/Progestin Replacement Study. Annals of Internal Medicine, 132, 689-696. https://doi.org/10.7326/0003-4819-132-9-200005020-00002

[16] Herrington, D.M., Vittinghoff, E., Howard, T.D., Major, D.A., Owen, J., Reboussin, D.M., et al. (2002) Factor V Leiden, Hormone Replacement Therapy, and Risk of Venous Thromboembolic Events in Women with Coronary Disease. Arteriosclerosis, Thrombosis, and Vascular Biology, 22, 1012-1017. https://doi.org/10.1161/01.ATV.0000018301.91721.94

[17] Hoibraaten, E., Qvigstad, E., Arnesen, H., Larsen, S., Wickstrom, E. and Sandset, P.M. (2000) Increased Risk of Recurrent Venous Thromboembolism during Hormone Replacement Therapy. Thrombosis and Haemostasis, 84, 961-967.

[18] Michalsen, B.T., Gherezghiher, T.B., Choi, J., Esala, R., Chandrasena, P., Qin, Z., Thatcher, G.R.J. and Bolton, J.L. (2012) The Selective Estrogen Receptor Modulator (SERM) Lasofoxifene Forms Reactive Quinones Similar to Estradiol. Chemical Research in Toxicology, 25, 1472-1483. https://doi.org/10.1021/tx300142h

[19] Trémollières, F. and Ribot, C. (2006) Indications du raloxifène chez la femme ménopausée. Gynécologie Obstétrique \& Fertilité, 34, 147-153.

https://doi.org/10.1016/j.gyobfe.2005.12.021

[20] Barrett-Connor, E., Mosca, L., Collins, P., Geiger, M.J., Grady, D., Kornitzer, M., et al. (2006) Effects of Raloxifene on Cardiovascular Events and Breast Cancer in Postmenopausal Women. The New England Journal of Medicine, 355, 125-137. https://doi.org/10.1056/NEJMoa062462

[21] Adomaityte, J., Farooq, M. and Qayyum, R. (2008) Effect of Raloxifene Therapy on Venous Thromboembolism in Postmenopausal Women. A Meta-Analysis. Thrombosis and Haemostasis, 99, 338-342.

[22] Duvernoy, C.S., Yeo, A.A., Wong, M., Cox, D.A. and Kim, H.M. (2010) Antiplatelet Therapy Use and the Risk of Venous Thromboembolic Events in the Raloxifene Use for the Heart (RUTH) Trial. Journal of Women's Health, 19, 1459-1465. 
https://doi.org/10.1089/jwh.2009.1687

[23] Meunier, P.J. (2006) Strontium Ranelate. Revue du Rhumatisme, 73, 834-837. https://doi.org/10.1016/j.rhum.2006.05.008

[24] Reginster, J.Y., Seeman, E., DeVernejoul, M.C., Adami, S., Compston, J., Phenekos, C., et al. (2005) Strontium Ranelate Reduces the Risk of Non Vertebral Fractures in Postmenopausal Women with Osteoporosis: Treatment of Peripheral Osteoporosis (Tropos Study). The Journal of Clinical Endocrinology \& Metabolism, 90, 2816-2822. https://doi.org/10.1210/jc.2004-1774

[25] Chaabane, A., Aouam, K., Ben Fredj, N. and Boughattas, N.A. (2010) Dress Syndrome: Étude de 11 cas et revue de la littérature. Therapie, 65, 443-450. https://doi.org/10.2515/therapie/2010072

[26] Pierre, A., Bera, J. and Autret-Leca, E. (2011) Ranélate de strontium (Protelos): Effets indésirables rapportés en France. La Presse Médicale, 40, 453-462. https://doi.org/10.1016/j.lpm.2011.07.010

[27] Bayhan, I., Uygur, D., Ugurlu, N. and Ozaksit, G. (2009) Strontium Ranelate Decreases Plasma Homocysteine Levels in Postmenopausal Osteoporotic Women. Rheumatology International, 29, 263-266. https://doi.org/10.1007/s00296-008-0693-6

[28] Grosso, A., Douglas, I., Hingorani, A., MacAllister, R. and Smeeth, L. (2008) Post-Marketing Assessment of the Safety of Strontium Ranelate; A Novel Case-Only Approach to the Early Detection of Adverse Drug Reactions. British Journal of Clinical Pharmacology, 66, 689-694.

[29] Audran, M., Jakob, F.J., Palacios, S., Brandi, M.L., Broll, L., Hamdy, N.A.T., et al. (2013) A Large Prospective European Cohort Study of Patients Treated with Strontium Ranelate and Followed up over 3 Years. Rheumatology International, 33, 2231-2239. https://doi.org/10.1007/s00296-012-2594-y

\section{Abbreviation Note List}

NIH: National Institue of Health

WHO: World Health Organisation

THM: Hormone Therapy in Menopause

WHI: World Health Institue

VTE: Venous Thromboembolism

SERMs: Selective Estrogen Receptor Modulators

BMD: Bone Mineral Density

RS: Stontium Ranelate

AFSSAPS: The French Agency for Health Safety of Health Products

DRESS: Drug Reaction with Eosinophilia and Systemic Symptoms 